\title{
Allergen Specific Immunotherapy in Asthma
}

\section{Marcello Mincarini, Anthi Rogkakou, Francesco Balbi and Giovanni Passalacqua*}

Allergy and Respiratory Diseases, IRCCS San Martino-IST-University of Genoa, Italy

\begin{abstract}
The use of allergen Specific Immunotherapy (SIT) to treat allergic asthma is still a matter of scientific debate. Currently, there are few studies specifically designed to evaluate asthma, and few studies had a formal sample size calculation, or objective parameters of pulmonary function assessed. On the other hand, there are good quality trials with both Subcutaneous Immuno-therapy (SCIT) and Sublingual Immunotherapy (SLIT) in allergic rhinitis, where asthma symptoms were also evaluated, if present. These studies consistently reported positive results. Moreover, several favourable meta-analyses are available, although their validity is limited by the great heterogeneity of the trials included. The disease modifying effect of SIT that is the capacity of preventing asthma onset should be also taken into account.

Concerning the safety, fatalities seem to be an exceptional event, and in Europe no fatality has been reported over the last two decades. Uncontrolled asthma is universally recognized as the most important risk factor for severe adverse events.

In conclusion, both SLIT and SCIT can be used in asthma associated with rhinitis (which is the most common condition), provided that asthma is adequately controlled by pharmacotherapy. In such case, a measurable clinical benefit on asthma symptoms can be expected. Nonetheless, SIT cannot be presently recommended as single therapy when asthma is the unique manifestation of respiratory allergy.
\end{abstract}

Keywords: Allergen-specific immunotherapy; Allergic asthma; Efficacy; Safety

\section{Introduction}

The use of allergen-Specific Immunotherapy (SIT) to treat asthma remains one of the most debated aspects in the field since several decades. The available guidelines provide no clear or unequivocal indication, stating only that SIT is specific for the allergen causing the allergic disease (rhinitis and/or asthma) and not for the disease itself [1]. Nonetheless, in the majority of the clinical trials, the efficacy of SIT has been evaluated separately for the two disorders, rhinitis and asthma, [27] and only few trials were specifically designed to evaluate the impact of SIT on asthma. This is due to the fact that in real life, isolated allergic asthma without rhinitis is infrequent and more than $30 \%$ of patients with allergic rhinitis also suffer from allergic asthma [8]. Another problem is that none of the trials evaluating asthma symptoms has been adequately designed and reported. A sample size calculation and a power analysis based on asthma symptoms alone were not ever used as primary outcome in any trial [9]. Moreover, a formal consensus on which measurement parameter for evaluating asthma should be chosen is still missing. In this regard, asthma symptoms, rescue medications intake, combined scores, asthma-free days, asthma exacerbations are all equally reasonable choices [10], however, objective functional pulmonary measurements such as Forced Expiratory Volume in one second (FEV1) were carried out only sporadically [11].

Currently, our knowledge on the use of SIT in asthma is based mostly on old clinical trials with SCIT, and on few recent trials conducted with SLIT, in rhinitis patients with concomitant asthma. Regardless of these limits, and the possible confounding factors, there is some evidence available to derive at least provisional conclusions.

\section{SCIT and SLIT in Asthma}

There are numerous clinical trials of SCIT in asthma published before 1990, most of them, involving a small number of patients. The largest review concerning asthma includes 88 clinical trials [12]. Many of these studies were not specifically designed for asthma, but had asthma symptoms reported. Although there are heavy methodological limitations (small samples, no power calculation, variable inclusion criteria) the above mentioned studies substantially agree on the clinical efficacy of SCIT in asthma induced by the most common allergens (grass, mite, pet dander), while about 25\% of the studies mentioned in the reviews $[1,13,14]$ failed to demonstrate a significant difference in clinical efficacy between placebo and active groups. The studies performed more recently, continued to have design limitations, without a formal sample size calculation, with inclusion criteria and outcomes largely variable and with a methodological quality often low [11]. Nonetheless the majority of the recent trials of SCIT including also asthmatic patients were able to show an improvement of asthma symptoms, and some also demonstrated a reduction in antiasthma drugs consumption. Lung function parameters (either FEV1 or PEFR) were measured only in few trials [15-20] with controversial results, but some trials reported a significant decrease in bronchial specific and non-specific responsiveness [11,12]. The first meta-analysis of SCIT in asthma took into account of 20 studies either controlled or not [21]. The same meta-analysis was updated again very recently expanded in 88 trials (70 randomized and placebo controlled) [12], with only 6 trials receiving the maximum score of 5 points at the Jadad scale, which considers the quality of blinding, randomisation, allocation of patients (from 0 to a maximum of 5). The effect of SCIT on asthma

*Corresponding author: Giovanni Passalacqua, Allergy and Respiratory Diseases University of Genoa, Padiglione Maragliano, L.go R.Benzi 10, 16132 Genoa, Italy, Tel 390103538933 ; Fax : 390103538904 ; E-mail: passalacqua@unige.it

Received February 25, 2014; Accepted September 06, 2014; Published September 13, 2014

Citation: Mincarini M, Rogkakou A, Balbi F, Passalacqua G (2014) Allergen Specific Immunotherapy in Asthma. J Allergy Ther 5: 190. doi:10.4172/21556121.1000190

Copyright: (c) 2014 Mincarini M, et al. This is an open-access article distributed under the terms of the Creative Commons Attribution License, which permits unrestricted use, distribution, and reproduction in any medium, provided the original author and source are credited. 
medication was also significant and a significant reduction in allergenspecific bronchial responses (measured by the threshold eliciting dose) was consistently shown. The heterogeneity of the studies was high, thus limiting the strength of the conclusions that could be drawn from the meta-analysis.

Sublingual immunotherapy has been introduced more recently as an alternative route of allergen administration. At present more than 70 randomized controlled trials are available [12], none of them formally sized and adequately powered for asthma. Some trials, conducted mainly in pediatric population (Table 1), were explicitly designed to include also the effects on asthma symptoms [22-27]. Regarding those trials, three of them $[22,24,27]$ failed to detect any effect on asthma symptoms due to the randomization of almost symptom-free patients (active patients and controls had almost no asthma symptoms at baseline or during the trial). Despite the high heterogeneity of the trials, as previously mentioned, various meta-analyses confirmed the clinical effect over placebo also for SLIT in asthma $[28,29]$. One of the major problems of SIT meta-analyses is that they often put together studies using different allergens (i.e. mites and pollens). Very recently, this aspect was addressed by two analyses, one restricted to mite extracts [30] and one to grass extracts [31]. The meta-analysis for dust mites included 9 trials that evaluated asthma symptoms and medication requirements. The results demonstrated a significant reduction versus placebo in both symptom scores $(\mathrm{p}=0.02)$ and medication use $(\mathrm{p}=0.02)$. Similar to other analyses, there was a high heterogeneity $\left(\mathrm{I}^{2}>90 \%\right)$ across studies. On the other hand the meta-analysis for grasses did not report specific results for asthma. As a matter of fact, it remains clear that there are differences in term of clinical response among different allergens, and that pollen-based SIT usually perform better than mitebased SIT [1].

\section{SIT versus Pharmacotheray}

The clinical effects of SIT, at variance with those using pharmacological treatment (bronchodilators, inhaled corticosteroids), cannot immediately be observed or measured. On the other hand SIT possesses an immuno-modulatory effect, that is profound and longlasting (Figure 1). Based on these observations, it is currently stated that SIT does not replace drugs but must be used in addition to them, in order to achieve a maximal therapeutic benefit [1]. However, a direct comparison between drugs and SIT remains a matter of debate. The main problems are that the clinical benefits of SIT appear only over a long time period, and that a rigorous head-to-head comparison would require a 3-5 year double blind and double dummy design. Thus, few studies have been performed, and none specifically designed for asthma. Rak et al. [32] demonstrated the superiority of nasal corticosteroids versus SIT in rhinitis but found that SIT could decrease the seasonal
BHR in asthmatic patients. In another open study [33] it was shown that that inhaled corticosteroids produced a more rapid and relevant benefit than SIT (based on symptoms' grading), but SIT maintained its effects after discontinuation. A trial conducted in asthmatic children [34] demonstrated that the clinical efficacy of SLIT plus fluticasone was equal to that of fluticasone alone, but that the addition of SLIT resulted in improvement in non-bronchial symptoms. Finally, a direct open randomized trial of SLIT versus inhaled budesonide as an add-on therapy in asthmatic patients, demonstrated an overall superiority of immunotherapy versus inhaled budesonide over time [35]. Certainly, all of these studies that were not randomized or designed as open trials which limit the methodological value of these observations.

\section{Other Effects?}

It is well known that patients affected by rhinitis have a major risk for the development of asthma [36]. The preventive effect of SIT was suggested more than 40 years ago in an observational open prospective study [37] in children and adolescents. SIT (either SCIT or SLIT) profoundly modifies the immune response to allergens (Figure 1), and was therefore hypothesized that it may alter the progression of the disease, reducing the risk of asthma onset. The effect was confirmed in more rigorous trials only during the last decades. The Preventative Allergy Treatment study enrolled 205 children (aged 6-10 years) suffering from allergic rhinitis randomized in two groups, one only with drug therapy alone and the other treated with drugs plus SCIT. After 3 years, the SCIT-treated patients had developed significantly less asthma than the control group, with an odds ratio of 2.5 [38]. The beneficial effect of SCIT lasted several years after discontinuation. A 10-year follow-up demonstrated significantly few numbers of patients with asthma in the SCIT-treated group [39]. The same effect was demonstrated in a randomized open trial with SLIT. The first open controlled study [40] involved 113 children aged 5-14 years affected by seasonal rhinitis due to grass pollen, randomly allocated to medications plus SLIT or medications only. After 3 years, 8/45 SLIT subjects and $18 / 44$ controls had developed asthma, with a relative risk of 3.8 for untreated patients. The other randomized open controlled trial [41] involved 216 children (5-17 years) suffering from rhinitis with/without intermittent asthma, randomly allocated 2:1 to drugs plus SLIT or drugs only. The prevalence of persistent asthma after 3 years of observation was $1.5 \%$ in the SLIT group and 30\% for the control group.

\section{The Safety of SLIT and SCIT in Asthma}

In the published studies, the frequency of SIT-induced Systemic Reactions (SRs) is variable, according to the allergen, the administration schedule, the extract and the dose. The majority of the data on the safety of SCIT pertain the surveys performed regularly in the United

\begin{tabular}{|c|c|c|c|c|c|}
\hline Author, year & Allergen & Active/placebo & Duration & Jadad score & Main results \\
\hline Hirsch, 1997 & Mite & $13 / 14$ & $1 \mathrm{yr}$ & $5 / 5$ & $\downarrow$ asthma symptom score; no change in bronchial reactivity \\
\hline Niu, 2006 & Mite & $56 / 54$ & 6 months & $4 / 5$ & $\begin{array}{l}\downarrow \text { asthma symptom score, daytime, nighttime symptoms and medication } \\
\text { score; no change FEV1 and oral steroids }\end{array}$ \\
\hline Lue, 2006 & Mite & $10 / 10$ & 8 months & $4 / 5$ & $\begin{array}{l}\downarrow \text { nighttime symptoms, } \uparrow F E V 1 \text { vs baseline; no change total symptom } \\
\text { score, medications and FEV1 vs placebo }\end{array}$ \\
\hline Dahl, 2006 & Grass & $74 / 40$ & 5 months & $5 / 5$ & no change symptoms and medications \\
\hline Pham Ti, 2007 & Mite & $55 / 56$ & 18 months & $4 / 5$ & no change symptoms, medications, FEV1, well days \\
\hline Stelmach, 2009 & Grass & $25 / 25$ & 2 season & $5 / 5$ & $\downarrow$ asthma symptoms and medications \\
\hline Bufe, 2009 & Grass & $126 / 127$ & 6 months & $5 / 5$ & $\downarrow$ asthma symptoms; no change medications \\
\hline
\end{tabular}

$\downarrow$ : decrease/reduction; $\uparrow$ : increase; FEV1: Forced Expiratory Volume in one second; PEFR: Peak Expiratory Flow Rate; QoL: Quality of Life.

Table 1: The most recent randomized controlled trials of SLIT considering also asthma symptoms in patients with concomitant rhinitis. 


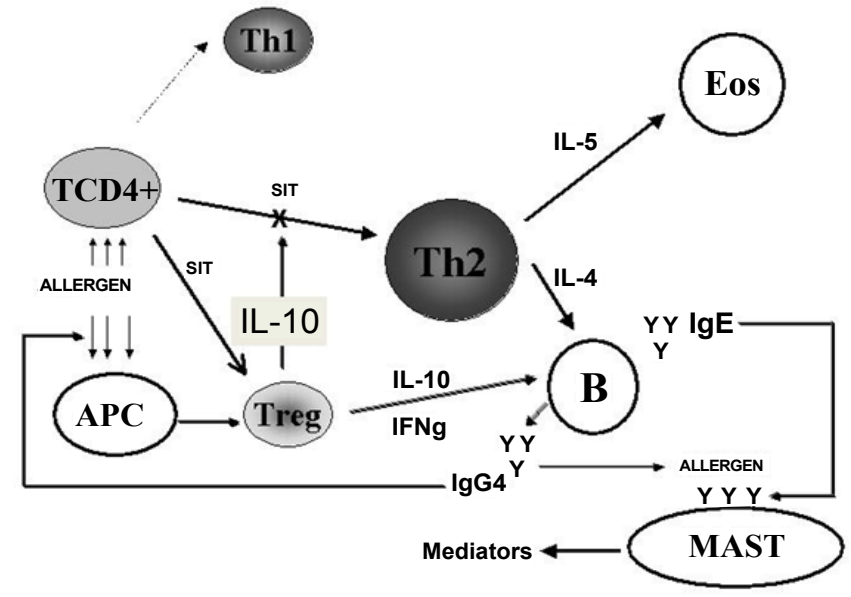

Figure 1: Th1: Tcell helper 1; Th2: T cell helper 2; Eos: Eosinophil; B: B lymphocyte; Treg: Regulatory T cell; APC: Antigen Presenting Cell; SIT: Specific Immunotherapy; MAST: Mast cell.

States [42-47], recording about 50 deaths over a 50 year period with a risk of one death every 2.500.000 injections and one near-fatal reaction per million injections. Fortunately, in the period 2008-2011 no further fatality due to SCIT was reported in the United States and SRs were about $0.1 \%$ of injection visits [48]. It must be underlined that the practice of SCIT differs between Europe and United States. In the USA, allergen mixtures and more concentrated allergen preparations are commonly used [49]. Thus, caution should be applied in transferring the USA data to other countries [50]. Less systematically collected data is available from Europe. Other than the well-known study that reported approximately 26 SCIT-induced deaths in UK in 1986 [51], fatalities have subsequently became extremely rare, without no report in the last two decades. An Italian survey [52], stated an overall rate of systemic reactions in about $5 \%$ of patients, and a Spanish survey, which included 423 patients [53] showed a prevalence of $3.7 \%$ reactions per patient. A recent multi-centre observational study [54] suggested that systemic reactions are slightly more frequent in rhinitis with asthma than in patients with rhinitis alone, although another retrospective study [55] found no significant association between SRs and asthma. According to the more recent meta-analysis of clinical trials [12], the occurrence of systemic reactions with SCIT (of any type and severity) is about 1 per 9 patients. Despite the overall rarity of deaths, all surveys agree that uncontrolled asthma is the predominant risk factor for adverse events, including asthma itself $[1,12]$. The safety of SLIT is overall superior to that of SCIT $[13,56]$, at least because no fatality has been reported until now, and only 12 cases of suspect/ascertained anaphylaxis have been described after 25 years of clinical use [57]. A controlled dose-finding study [58], involving 48 grass-allergic patients outside the pollen season and receiving daily up to $200 \mathrm{mcg} \mathrm{Phl} \mathrm{p} \mathrm{5}$, (about 40 times the amount given with one monthly injection) reported an occurrence of side effects in $74 \%$ patients, almost all local and mild or moderate in intensity. Dahl et al [24] specifically assessed the safety of SLIT in asthma. More than 100 grass-allergic asthmatics were enrolled and treated before the pollen season. The number of side effects possibly related to asthma (wheezing cough, dyspnoea) was similar between the active and placebo group, and there was no evidence of asthma aggravation. Only few large-scale surveys can assure reliable data on the prevalence, the nature and the severity of side effects. The lack of a universally accepted classification and grading system for SRs has recently been addressed by the World Allergy Organization, proposing a new classification for systemic reactions due to SCIT/SLIT [59] and for local reactions due to SLIT [60]. According to the available data, severe or uncontrolled asthma remains the principal risk factor for side effects due to SCIT. For practical reasons, this concept has been transferred to SLIT, although the clinical data do not clearly indicate severe asthma as a specific contraindication to SLIT [13]. In general, asthma is not an absolute contraindication to SCIT/SLIT, provided that the patient is well controlled with pharmacotherapy.

\section{Concluding Remarks. Where Do We Stand?}

Since year 2000, many guidelines and recommendations were prepared according to the Grading of Recommendations Assessment, Development and Evaluation (GRADE) system [61], which takes into account not only the assessment of the efficacy of a given intervention, but also the safety and the patient's preferences. Certainly, the first essential requirement is an adequate study methodology (e.g. sample size, outcome, selection criteria, randomization), not always respected in SIT trials in asthma, since many of the randomized controlled trials had important limitations (small number of patients, absence of objective measurement of lung function, no sample size calculation based on the objective parameters, variability of doses and protocols, lack of a true placebo control group). This is reflected in meta-analyses, where the overall positive clinical results are counterbalanced by the high heterogeneity of the studies. In fact, according to the GRADE rules, physicians and researchers are generally reluctant to clearly recommend the use of SIT in asthma [62], with few exceptions [63]. On the other hand, it would not be reasonable to neglect all the positive clinical data, produced so far in trials where asthma symptoms were adequately recorded. What we presently know is that for SCIT, uncontrolled asthma represents the only contraindication, although the same has not been clearly demonstrated for SLIT. Moreover, the disease-modifying and long-lasting effects of SIT in asthma prevention should be taken into account [64]. Also, the pharmaco-economical aspects should be taken into account, since it was suggested that SIT may result produce relevant saving (direct and indirect costs) in patients with allergic rhinitis and comorbid asthma $[65,66]$. What is clearly lacking is a predictive (either clinical or biological) parameter to anticipate the clinical outcomes of SIT in allergic patients, although attempts are ongoing to better define a phenotype-oriented profile [67]. According to the available evidence it should be stated that either SLIT or SCIT can be used together with asthma medications in patients affected by rhinitis and asthma, when the causal role of the allergen (pollens, mite or pets) is clearly confirmed. The recommendation of not giving SIT in patients with severe or uncontrolled asthma remains valid. Some unresolved questions remain: the optimal treatment schedule (pre-seasonal or continuous) [68], the optimal maintenance dose administered for SLIT for allergens other than grasses, the duration of treatment to obtain a satisfactory long term effect [69], and the appropriate use of objective outcomes in asthma. Finally, the most important question is to whose children with rhinitis only, SIT should be prescribed to achieve the relevant clinical effect of preventing the on future development of asthma.

\section{References}

1. WHO Position Paper. Allergen immunotherapy: therapeutical vaccines for allergic diseases. (Edn) Bousquet J, Lockey RF, Malling HJ (Eds) Allergy 54 $1-33$.

2. Bonifazi F, Bilò MB (1997) Efficacy of specific immunotherapy in allergic asthma: myth or reality? Allergy 52: 698-710. 
3. Cox L (2008) Allergen immunotherapy and asthma: efficacy, safety and other considerations. Allergy Asthma Proc 29: 580-589.

4. Nelson HS (2007) Allergen immunotherapy: where is it now? J Allergy Clin Immunol 119: 769-779.

5. Saltoun CA (2002) Update on efficacy of allergen immunotherapy for allergic rhinitis and asthma. Allergy Asthma Proc 23: 377-380.

6. Bousquet J, Demoly P, Michel FB (2001) Specific immunotherapy in rhinitis and asthma. Ann Allergy Asthma Immunol 87: 38-42.

7. Creticos PS (2000) The consideration of immunotherapy in the treatment of allergic asthma. J Allergy Clin Immunol 105: S559-574.

8. Cruz AA, Popov T, Pawankar R, Annesi-Maesano I, Fokkens W, et al. (2007) Common characteristics of upper and lower airways in rhinitis and asthma: ARIA update, in collaboration with GA(2)LEN. Allergy 62 Suppl 84: 1-41.

9. Bousquet PJ, Brozek J, Bachert C, Bieber T, Bonini S, et al. (2009) The CONSORT statement checklist in allergen-specific immunotherapy: a GA2LEN paper. Allergy 64: 1737-1745

10. Canonica GW, Baena-Cagnani CE, Bousquet J, Bousquet PJ, Lockey RF, et al. (2007) Recommendations for standardization of clinical trials with Allergen Specific Immunotherapy for respiratory allergy. A statement of a World Allergy Organization (WAO) taskforce. Allergy 62: 317-324.

11. Passalacqua G, Canonica GW (2011) Specific immunotherapy in asthma: efficacy and safety. Clin Exp Allergy 41: 1247-1255.

12. Abramson MJ, Puy RM, Weiner JM (2010) Injection allergen immunotherapy for asthma Cochrane Database Syst Rev 4:8

13. Canonica GW, Bousquet J, Casale T, Lockey RF, Baena-Cagnani CE, et al (2009) Sub-lingual immunotherapy: World Allergy Organization Position Pape 2009. Allergy 64 Suppl 91: 1-59.

14. Cox L, Nelson H, Lockey R, Calabria C, Chacko T, et al. (2011) Allergen immunotherapy: a practice parameter third update. J Allergy Clin Immunol 127 S1-55.

15. Paranos S, Petrovic S (1997) Early effects of rush immunotherapy with Dermatophagoidespteronyssinus in asthmatics. J Investig Allergol Clin Immunol 7: 588-595

16. Grembiale RD, Camporota L, Naty S, Tranfa CM, Djukanovic R, et al. (2000) Effects of specific immunotherapy in allergic rhinitic individuals with bronchial hyperresponsiveness. Am J Respir Crit Care Med 162: 2048-2052.

17. Varney VA, Tabbah K, Mavroleon G, Frew AJ (2003) Usefulness of specific immunotherapy in patients with severe perennial allergic rhinitis induced by house dust mite: a double-blind, randomized, placebo-controlled trial. Clin Exp Allergy 33: 1076-1082

18. Ferrer A, García-Sellés J (2003) Significant improvement in symptoms, skin test, and specific bronchial reactivity after 6 months of treatment with a depigmented, polymerized extract of Dermatophagoidespteronyssinus and $\mathrm{D}$. farinae. J Investig Allergol Clin Immunol. 13: 244-251

19. Wang H, Lin X, Hao C, Zhang C, Sun B (2006)Double-blind, placebo-controlled study of house dust mite immunotherapy in Chinese asthmatic patients. Allergy 61: 191-197

20. Tabar Al, Lizaso MT, García BE, Gómez B, Echechipía S (2008) Double-blind, placebo-controlled study of Alternariaalternata immunotherapy: clinical efficacy and safety. Pediatr Allergy Immunol 19: 67-75

21. Abramson A, Puy R, Weiner J (2000) Allergen immunotherapy for asthma Cochrane database of systematic reviews 2: CD 001186

22. Pham-Thi N, Scheinmann P, Fadel R, Combebias A, Andre C (2007) Assessment of sublingual immunotherapy efficacy in children with house dust mite-induced allergic asthma optimally controlled by pharmacologic treatment and mite-avoidance measures. Pediatr Allergy Immunol 18: 47-57

23. Hirsch T, Sähn M, Leupold W (1997) Double-blind placebo-controlled study of sublingual immunotherapy with house dust mite extract (D.pt.) in children. Pediatr Allergy Immunol 8: 21-27.

24. Dahl R, Stender A, Rak S (2006) Specific immunotherapy with SQ standardized grass allergen tablets in asthmatics with rhinoconjunctivitis. Allergy 61: 185190

25. Stelmach I, Kaczmarek-Wo $\AA^{\circ}$ niak J, Majak P, Olszowiec-Chlebna M, Jerzynska
$J$ (2009) Efficacy and safety of high-doses sublingual immunotherapy in ultrarush scheme in children allergic to grass pollen. Clin Exp Allergy 39: 401-408.

26. Bufe A, Eberle P, Franke-Beckmann E, Funck J, Kimmig M, et al. (2009) Safety and efficacy in children of an SQ-standardized grass allergen tablet for sublingual immunotherapy. J Allergy Clin Immunol 123: 167-173.

27. Niu CK, Chen WY, Huang JL, Lue KH, Wang JY (2006) Efficacy of sublingual immunotherapy with high-dose mite extracts in asthma: a multi-center, doubleblind, randomized, and placebo-controlled study in Taiwan. Respir Med 100: 1374-1383.

28. Calamita Z, Saconato H, Pelá AB, Atallah AN (2006) Efficacy of sublingual immunotherapy in asthma: systematic review of randomized-clinical trials using the Cochrane Collaboration method. Allergy 61: 1162-1172.

29. Penagos M, Passalacqua G, Compalati E, Tarantini F, Canonica GW (2008) Metaanalysis of the efficacy of sublingual immunotherapy in the treatment of allergic asthma in pediatric patients, 3 to 18 years of age. Chest 133: 599-609

30. Compalati E, Passalacqua G, Bonini M, Canonica GW (2009) The efficacy of sublingual immunotherapy for house dust mites respiratory allergy: results of a GA2LEN meta-analysis. Allergy 64: 1570-1579.

31. Di Bona D, Plaia A, Scafidi V, Leto-Barone MS, Di Lorenzo G (2010) Efficacy of sublingual immunotherapy with grass allergens for seasonal allergic rhinitis: a systematic review and meta-analysis. J Allergy Clin Immunol 126: 558-566.

32. Rak S, Heinrich C, Jacobsen L, Scheynius A, Venge P (2001)A double-blinded, comparative study of the effects of short preseason specific immunotherapy and topical steroids in patients with allergic rhinoconjunctivitis and asthma. $J$ Allergy Clin Immunol 108: 921-928

33. Shaikh WA (1997) Immunotherapy vs inhaled budesonide in bronchial asthma: an open, parallel, comparative trial. Clin Exp Allergy 27: 1279-1284.

34. Pajno GB, Vita D, Parmiani S, Caminiti L, La Grutta S, et al. (2003) Impact of sublingual immunotherapy on seasonal asthma and skin reactivity in children allergic to Parietaria pollen treated with inhaled fluticasone propionate. Clin Exp Allergy 33: 1641-1647.

35. Marogna M, Spadolini I, Massolo A, Berra D, Zanon P, et al. (2009) Long-term comparison of sublingual immunotherapy vs inhaled budesonide in patients with mild persistent asthma due to grass pollen. Ann Allergy Asthma Immuno 102: 69-75.

36. Shaaban R, Zureik M, Soussan D, Neukirch C, Heinrich J, et al. (2008) Rhinitis and onset of asthma: a longitudinal population-based study. Lancet 372: 1049 1057.

37. Johnstone DE, Dutton A (1968) The value of hyposensitization therapy for bronchial asthma in children--a 14-year study. Pediatrics 42: 793-802.

38. Möller C, Dreborg S, Ferdousi HA, Halken S, Høst A, et al. (2002) Pollen immunotherapy reduces the development of asthma in children with seasonal rhinoconjunctivitis (the PAT-study). J Allergy Clin Immunol 109: 251-256.

39. Jacobsen L, Niggemann B, Dreborg S, Ferdousi HA, Halken S, et al. (2007) Specific immunotherapy has long-term preventive effect of seasonal and perennial asthma: 10-year follow-up on the PAT study. Allergy 62: 943-948.

40. Novembre E, Galli E, Landi F, Caffarelli C, Pifferi M, et al. (2004) Coseasona sublingual immunotherapy reduces the development of asthma in children with allergic rhinoconjunctivitis. J Allergy Clin Immunol 114: 851-857.

41. Marogna M, Tomassetti D, Bernasconi A, Colombo F, Massolo A, et al (2008) Preventive effects of sublingual immunotherapy in childhood: an open randomized controlled study. Ann Allergy Asthma Immunol 101: 206-211.

42. Lockey RF, Benedict LM, Turkeltaub PC, Bukantz SC (1987) Fatalities from immunotherapy (IT) and skin testing (ST) J Allergy Clin Immunol 79: 660-677.

43. Reid MJ, Lockey RF, Turkeltaub PC, Platts-Mills TA (1993) Survey of fatalities from skin testing and immunotherapy 1985-1989. J Allergy Clin Immunol 92 $6-15$.

44. Bernstein DI, Wanner M, Borish L, Liss GM; Immunotherapy Committee American Academy of Allergy, et al. (2004) Twelve-year survey of fatal reactions to allergen injections and skin testing: 1990-2001. J Allergy Clin Immunol 113: 1129-1136.

45. Lin MS, Tanner E, Lynn J, Friday GA Jr (1993) Nonfatal systemic allergic reactions induced by skin testing and immunotherapy. Ann Allergy 71: 557-562.

46. Amin HS, Liss GM, Bernstein DI (2006) Evaluation of near-fatal reactions to 
Citation: Mincarini M, Rogkakou A, Balbi F, Passalacqua G (2014) Allergen Specific Immunotherapy in Asthma. J Allergy Ther 5: 190. doi:10.4172/21556121.1000190

Page 5 of 5

allergen immunotherapy injections. J Allergy Clin Immunol 117: 169-175.

47. Tinkelman DG, Cole WQ 3rd, Tunno J (1995) Immunotherapy: a one-year prospective study to evaluate risk factors of systemic reactions. J Allergy Clin Immunol 95: 8-14.

48. Epstein TG, Liss GM, Murphy-Berendts K, Bernstein DI (2013) AAAAI and ACAAl surveillance study of subcutaneous immunotherapy, Year 3: what practices modify the risk of systemic reactions? Ann Allergy Asthma Immunol 110: $274-278,278$

49. Cox L, Jacobsen $L$ (2009) Comparison of allergen immunotherapy practice patterns in the United States and Europe. Ann Allergy Asthma Immunol 103: 451-459.

50. Baena-Cagnani CE, LarenasLinnemann D, Gómez M, Díaz SG, Solé D, et al. (2013) Allergy training and immunotherapy in Latin America: results of a regional overview. Ann Allergy Asthma Immunol 111: 415-419.

51. Committee on the Safety of Medicines. Desensitizing vaccines. (1989) BM 293: 948.

52. Ragusa FV, Passalacqua G, Gambardella R, Campanari S, Barbieri MM, et al. (1997) Nonfatal systemic reactions to subcutaneous immunotherapy: a 10-year experience. J Investig Allergol Clin Immunol 7: 151-154.

53. Moreno C, Cuesta-Herranza J, Fernandez-Tavora L, Alvarez-Cuesta E (2004) Immunotherapy safety: a prospective multi-centric monitoring study of biologically standardized therapeutic vaccines for allergic diseases. Clin Exp Allergy 34: 527-531

54. Schiappoli M, Ridolo E, Senna G, Alesina R, Antonicelli L, et al. (2009) A prospective Italian survey on the safety of subcutaneous immunotherapy for respiratory allergy. Clin Exp Allergy 39: 1569-1574.

55. Rank MA, Oslie CL, Krogman JL, Park MA, Li JT (2008) Allergen immunotherapy safety: characterizing systemic reactions and identifying risk factors. Allergy Asthma Proc 29: 400-405.

56. Cox LS, LarenasLinnemann D, Nolte H, Weldon D, Finegold I, et al. (2006) Sublingual immunotherapy: a comprehensive review. J Allergy Clinlmmunol 117: $1021-1035$

57. Calderón MA, Simons FE, Malling HJ, Lockey RF, Moingeon P, et al. (2012)
Sublingual allergen immunotherapy: mode of action and its relationship with the safety profile. Allergy $67: 302-311$

58. Kleine-Tebbe J, Ribel M, Herold DA (2006) Safety of a SQ-standardised grass allergen tablet for sublingual immunotherapy: a randomized, placebo-controlled trial. Allergy 61: 181-184.

59. Cox L, Larenas-Linnemann D, Lockey RF, Passalacqua G (2010) Speaking the same language: The World Allergy Organization Subcutaneous Immunotherapy Systemic Reaction Grading System. J Allergy Clin Immunol 125: 569-574, 574

60. Passalacqua G, Baena-Cagnani CE, Bousquet J, Canonica GW Casale TB, et al. (2013) Grading local side effects of sublingual immunotherapy for respiratory allergy: speaking the same language. J Allergy Clin Immunol 132: 93-98.

61. Brozek JL, Baena-Cagnani CE, Bonini S, Canonica GW, Rasi G, et al. (2008) Methodology for development of the Allergic Rhinitis and its Impact on Asthma guideline 2008 update. Allergy 63: 38-46.

62. Brozek JL, Bousquet J, Baena-Cagnani CE, Bonini S, Canonica GW (2010) Grading of Recommendations Assessment, Development and Evaluation Working Group. Allergic Rhinitis and its Impact on Asthma (ARIA) guidelines J Allergy Clin Immunol 126: 466-470

63. NHLBI Guidelines for the Diagnosis and Treatment of Asthma.

64. Passalacqua G (2011) Specific immunotherapy: beyond the clinical scores Ann Allergy Asthma Immunol 107: 401-406.

65. Berto P, Frati F, Incorvaia C (2008) Economic studies of immunotherapy: a review. Curr Opin Allergy Clin Immunol 8: 585-589.

66. Hankin CS, Cox L (2014) Allergy immunotherapy: what is the evidence for cost saving? Curr Opin Allergy Clin Immunol 14: 363-370.

67. Peng W, Liu E (2013) Factors influencing the response to specific immunotherapy for asthma in children aged $5-16$ years. Pediatr Int 55: 680-684.

68. Pajno G, Caminiti L, Vita D, Crisafulli G, Valenzise M (2011) Direct comparison between continuous and co-seasonal regimen for sublingual immunotherapy in children with grass allergy. Pediatr Allergy immunol 22: 803-807

69. Marogna M, Spadolini I, Massolo A, Canonica GW, Passalacqua G (2010) Long-lasting effects of sublingual immunotherapy according to its duration: a 15-year prospective study. J Allergy Clin Immunol 126: 969-975. 